\title{
The estimated prevalence of exposure to asthmagens in the Australian workforce, 2014
}

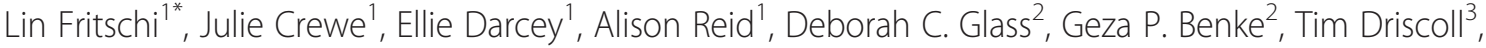 \\ Susan Peters ${ }^{4}$, Si Si ${ }^{1}$, Michael J. Abramson ${ }^{2}$ and Renee N. Carey ${ }^{1}$
}

\begin{abstract}
Background: There is very little information available on a national level as to the number of people exposed to specific asthmagens in workplaces.

Methods: We conducted a national telephone survey in Australia to investigate the prevalence of current occupational exposure to 277 asthmagens, assembled into 27 groups. Demographic and current job information were obtained. A web-based tool, OccIDEAS, was used to collect job task information and assign exposure to each asthmagen group.

Results: In the Australian Workplace Exposure Study - Asthma (AWES- Asthma) we interviewed 4878 participants (2441 male and 2437 female). Exposure to at least one asthmagen was more common among men (47\%) than women $(40 \%)$. Extrapolated to the Australian population, approximately 2.8 million men and 1.7 million women were estimated to be exposed. Among men, the most common exposures were bioaerosols (29\%) and metals $(27 \%)$, whilst the most common exposures among women were latex (25\%) and industrial cleaning and sterilising agents (20\%).
\end{abstract}

Conclusions: This study provides information about the prevalence of exposure to asthmagens in Australian workplaces which will be useful in setting priorities for control and prevention of occupational asthma.

Keywords: Occupational asthma, Surveillance, Workplace exposure

\section{Background}

Work-related (or occupational) asthma is caused by exposure to agents in an occupational setting and includes both work-aggravated asthma (in which workplace exposures provoke or exacerbate symptoms of pre-existing asthma) and newly-occurring occupational asthma [1]. Occupational asthma is divided into two groups: allergic and non-allergic [2]. Allergic occupational asthma is caused by exposures to agents which sensitize the airways. The airways then react to subsequent additional exposure to that agent and may also react to other agents and triggers. Non-allergic occupational asthma is less common (perhaps $10 \%$ of all occupational asthma) and is a result

\footnotetext{
* Correspondence: lin.fritschi@curtin.edu.au

'School of Public Health, Curtin University, GPO Box U1987, Perth, Western

Australia 6845, Australia

Full list of author information is available at the end of the article
}

of exposure to high levels of a respiratory irritant (such as hydrogen chloride, ammonia, chlorine etc).

A review of international studies estimated that about 16-17\% of adult onset asthma was caused by occupational exposures [3]. Work-related asthma is one of the few preventable types of asthma. For example, a study in the aluminium industry showed that the incidence of occupational asthma in seven smelters had declined from $9.46 / 1000$ per year in 1992 to $0.36 / 1000$ per year in 2006; a $96.2 \%$ reduction [4]. This reduction was ascribed to improvements in control of exposures, respiratory protection and pre-placement medical assessments.

Several hundred workplace agents have been found to cause occupational asthma, including organic dusts (e.g. wood, flour, animal dander), and chemicals such as isocyanates and glutaraldehyde [5]. Exposure to asthmagens may occur in many occupations including farming, 
painting, food preparation, nursing and laboratory work [6]. In Finland, it was estimated in 1992 that about $13 \%$ of the workforce were exposed to allergens at work and $30 \%$ were exposed to respiratory contaminants [7]. In the European Community Respiratory Health Survey, about half of the sample reported exposure to "vapors, gas, dust or fumes" in their current job [8]. Similarly, about two thirds of a Norwegian cohort were assessed by a job exposure matrix as being exposed at some time during their working life to at least one of the following agents: biological dust, mineral dust, and gas and fumes [9]. None of these studies identified specific asthmagens and not all dusts are asthmagenic. In New Zealand, 55 \% of the population self-reported exposure to at least one group of asthmagens [10]. There are currently no estimates of the number of people exposed to specific asthmagens in workplaces in Australia.

We recently developed a comprehensive and inclusive list of asthmagens relevant for Australian workplaces [11]. It contained 277 asthmagens (in 27 groups) (Table 3) which had been identified from a number of published sources and were all deemed to meet three criteria: (1) there was evidence that the agent was an asthmagen; (2) the agent was used in occupational circumstances; and (3) it was potentially present in Australian workplaces. We subsequently undertook a national cross-sectional survey (The Australian Workplace Exposures Study - Asthma or AWES-Asthma) in 2014 to investigate the prevalence of occupational exposures to these asthmagens. This paper reports the methods and results of this survey.

\section{Methods}

\section{Subject selection}

The survey sample list was obtained from a commercial survey sampling company and included both landline and mobile telephone numbers, along with postal addresses and postcodes. We requested a randomized sample, stratified to be broadly proportional to the 2011 distribution of the Australian workforce by state and territory [12]. Unfortunately, we discovered after the data collection was complete that the sample provided was not random (56\% of the last names selected began with $\mathrm{L}$ and $25 \%$ began with $\mathrm{M})$. The effect of this on our results is not known but is not likely to be substantial.

Each number was telephoned and asked if there was anyone on that number aged 18 to 64 years and currently in paid employment (having worked for one hour or more for pay in the previous week [13]). Exclusion criteria were if the respondent did not have a sufficiently good understanding of spoken English, had a hearing disability or was too ill to complete the telephone survey. Due to the reluctance of male respondents to contribute to research surveys [14] and our previous experience [15] we used a modified interview request for landlines. That is, if there were both male and female eligible workers in a household, the interviewer would request a male in 6 out of 7 calls.

\section{Data collection}

All data were collected by experienced telephone survey staff. Each interview was designed to be completed in less than $15 \mathrm{~min}$. Phone calls were made between $9 \mathrm{am}$ and $8 \mathrm{pm}$ on weekday evenings and between $10 \mathrm{am}$ and $5 \mathrm{pm}$ on weekends.

The interviewers recorded demographic information including age, gender, country of birth, year of arrival in Australia, highest education level achieved, personal and co-workers' smoking status, business size and whether the respondent was aware of dust or gas monitoring in their work spaces. From the respondent's residential postcode, we derived the socio-economic indexes for areas (SEIFA) disadvantage score [16] and the accessibility/remoteness index of Australia (ARIA+) score [17].

Preliminary information on the main job for each person was collected to establish whether the respondent's occupation corresponded to one of the categories of employment that were predetermined by occupational hygienists to be unlikely to result in exposure to any of the 277 asthmagens. These were: office and clerical workers, data processors, flight attendants or pilots, retail sales workers other than food outlets, customer service workers, bank or postal service staff, and correctional services officers. The respondents who were employed in any one of these categories were classified as unexposed and the interview ended at that point.

For the remaining workers, additional information regarding their current job was obtained, including job title, industry type, number of hours worked per week and weeks worked per year. Using this information about a person's job and industry type, interviewers assigned the respondents to one of 52 job specific modules (JSMs) within the web-based tool OccIDEAS [18]. The JSMs were individually developed for specific jobs where it was considered that exposure to any of the asthmagens could occur and which were reasonably common in Australia. Where a job did not fit any of the 52 JSMs, a Generic JSM was assigned to collect information about tasks commonly carried out.

\section{Exposure assessments}

Each JSM within OccIDEAS contained questions relating to specific tasks which had been identified as determinants of exposure to one or more of the asthmagen groups based on published literature, material data sheets and expert knowledge. Algorithms based on literature and expert opinion were used to assign the likelihood of exposure to each of the listed asthmagen groups 
(either 'no', 'possible' or 'probable'). All automatic assessments were reviewed by project staff and rules were changed where necessary and appropriate. Any such changes were then applied to all assessments using the revised rule. The reviewers also used all available information to categorize the "possible" exposures into either probable or no exposure. Where the information was inadequate to be confident of exposure, we classified the remaining 873 possible assessments as unexposed $(0.7 \%$ of all assessments).

\section{Statistical analysis}

Each of the respondents' job titles were coded using the Australian and New Zealand Standard Classification of Occupations (ANZSCO) [19]. These codes were then classified into 24 occupational groups (Table 1), containing occupations which were broadly similar with regard to exposure to the asthmagen groups.

All analyses were conducted using Stata v14 [20]. Prevalence of any exposure was defined as the proportion of respondents assessed as being probably exposed to at least one of the listed asthmagens in their current job. A dichotomous measure of exposure was used. Odds Ratios (ORs) and $95 \%$ confidence intervals (CIs) were estimated using logistic regression to determine which, if any, demographic factors were associated with any exposure. For the continuous variable age we categorized the data using cut-offs of 35 and 50 based on the methods of Abdolell [21].

We stratified all analyses by gender due to the different profiles of occupation and exposure between genders. Where there was a statistically significant difference between our sample and the labour force, we used raked-weighting [22] to adjust the survey data such that the data structure was made similar to the national labour force population structure [23] in terms of sociodemographic indicators (age group and remoteness for both genders and administrative job (yes/no) for women).

As a visual demonstration of the patterns of exposure among the occupational groups, we calculated Euclidean distances. To do this we compared the differences between prevalences in groups and ranked the groups according to the size of those differences. First we compared the prevalence of all exposures combined in each occupational group with the prevalence of all exposures combined in the manager/administration group (which had low prevalence of exposure). Next we examined each occupational group in turn and compared the prevalence of each exposure group with the prevalence of the asthmagen group "Drugs" (which had low prevalence in all occupational groups). Euclidean distances are used to group similar ranked cells on both axes. In the upper right corner, occupational and asthmagen groups with the highest prevalence are clustered together.

\section{Ethics, consent and permissions}

This study was approved by the Curtin University $\mathrm{Hu}$ man Research Ethics Committee. Informed consent by all participants was presumed by the approval to proceed with the survey questions after a description of the study had been provided.

\section{Results}

A total of 38,051 telephone numbers were called over the 6 month period of the survey. No response was recorded after 10 call attempts from 10,284 households ("unknown households"), 21,429 contacts were deemed ineligible and 1318 refused to participate (Fig. 1). Job information was incomplete for 118 people who were interviewed. Complete interviews were obtained from 4878 workers (2441 males and 2437 females) resulting in a response fraction (completed interviews/eligible and unknown households) of $29 \%$ and a cooperation fraction (completed interviews/eligible households) of $77 \%$.

The study population was similar to the Australian working population in terms of state of residence, country of birth (Australia or other), education and socioeconomic status of residence (Table 1). Our sample under-represented younger workers (18-34 years), and those living in major cities. Among occupational groups, our sample over-represented manager/administration workers among males.

Amongst males, in the unadjusted analyses, exposure was more common amongst those aged less than 35 years, those born in Australia, those with a vocational qualification or no post-secondary qualifications, those living in Victoria, those in the lowest SEIFA residential quintiles and those living outside major cities (Table 2). When we adjusted for demographic characteristics and occupational groups, exposure to at least one asthmagen was significantly more common among men with a vocational qualification and those living in Victoria or Tasmania. Among females, after adjustment, only living in an outer regional/remote or very remote area was statistically associated with a higher prevalence of exposure to at least one asthmagen (Table 2).

As well as the above analysis of exposure to any asthmagen group, we also examined the patterns of exposure to individual agents. Exposure to one or more asthmagens was more common among males $(47 \%)$ than females (40 \%). When extrapolated to the Australian population, about 4.4 million people ( 2.8 million males and 1.7 million females) were estimated to be exposed to one or more asthmagen at work. Amongst occupational groups with more than 50 male respondents, exposure to at least one of the asthmagens was most common 
Table 1 Comparisons between the AWES-Asthma sample and the Australian workforce [23] by gender

\begin{tabular}{|c|c|c|c|c|c|c|c|c|c|c|}
\hline \multirow{3}{*}{ Demographic Characteristic } & \multicolumn{4}{|l|}{ Males } & \multirow{3}{*}{$p$-value } & \multicolumn{4}{|c|}{ Females } & \multirow{3}{*}{$p$-value } \\
\hline & \multicolumn{2}{|c|}{ AWES Sample } & \multicolumn{2}{|c|}{ Australian Census } & & \multicolumn{2}{|c|}{ AWES Sample } & \multicolumn{2}{|c|}{ Australian Census } & \\
\hline & $\mathrm{n}$ & $\%$ & $\mathrm{n}$ & $\%$ & & $n$ & $\%$ & $n$ & $\%$ & \\
\hline Total & 2441 & & 5040849 & & & 2437 & & 4441578 & & \\
\hline Age & & & & & $<0.001$ & & & & & $<0.001$ \\
\hline $18-34$ years & 301 & $12 \%$ & 1844844 & $37 \%$ & & 227 & $9 \%$ & 1634880 & $37 \%$ & \\
\hline $35-50$ years & 1050 & $43 \%$ & 1957490 & $39 \%$ & & 1115 & $46 \%$ & 1751048 & $39 \%$ & \\
\hline $51-64$ years & 1090 & $45 \%$ & 1238515 & $25 \%$ & & 1095 & $45 \%$ & 1055650 & $24 \%$ & \\
\hline State & & & & & 1.0 & & & & & 1.0 \\
\hline New South Wales & 767 & $31 \%$ & 1573658 & $31 \%$ & & 760 & $31 \%$ & 1388132 & $31 \%$ & \\
\hline Victoria & 595 & $24 \%$ & 1272872 & $25 \%$ & & 637 & $26 \%$ & 1121241 & $25 \%$ & \\
\hline Queensland & 471 & $19 \%$ & 1012186 & $20 \%$ & & 481 & $20 \%$ & 901345 & $20 \%$ & \\
\hline South Australia & 166 & $7 \%$ & 367283 & $7 \%$ & & 180 & $7 \%$ & 328939 & $7 \%$ & \\
\hline Western Australia & 308 & $13 \%$ & 563640 & $11 \%$ & & 259 & $11 \%$ & 469323 & $11 \%$ & \\
\hline Tasmania & 61 & $2 \%$ & 105692 & $2 \%$ & & 46 & $2 \%$ & 98326 & $2 \%$ & \\
\hline Australian Capital Territory & 47 & $2 \%$ & 95380 & $2 \%$ & & 44 & $2 \%$ & 90729 & $2 \%$ & \\
\hline Northern Territory & 26 & $1 \%$ & 50138 & $1 \%$ & & 30 & $1 \%$ & 43543 & $1 \%$ & \\
\hline Country of Birth & & & & & 0.06 & & & & & 0.10 \\
\hline Australia & 1913 & $78 \%$ & 3529539 & $70 \%$ & & 1937 & $79 \%$ & 3178745 & $72 \%$ & \\
\hline Other & 524 & $21 \%$ & 1511310 & $30 \%$ & & 496 & $20 \%$ & 1262833 & $28 \%$ & \\
\hline Education & & & & & 0.12 & & & & & 0.12 \\
\hline High school or lower & 962 & $39 \%$ & 1949397 & $39 \%$ & & 806 & $33 \%$ & 1822204 & $41 \%$ & \\
\hline Vocational/Trade & 720 & $29 \%$ & 1904288 & $38 \%$ & & 684 & $28 \%$ & 1269804 & $29 \%$ & \\
\hline Bachelor or higher & 758 & $31 \%$ & 1187164 & $24 \%$ & & 946 & $39 \%$ & 1349570 & $30 \%$ & \\
\hline Socioeconomic status & & & & & 0.57 & & & & & 0.32 \\
\hline Highest Quintile (Most advantaged) & 560 & $23 \%$ & 1403088 & $28 \%$ & & 519 & $21 \%$ & 1288370 & $29 \%$ & \\
\hline Fourth & 483 & $20 \%$ & 1146277 & $23 \%$ & & 515 & $21 \%$ & 1018968 & $23 \%$ & \\
\hline Third & 519 & $21 \%$ & 1026527 & $21 \%$ & & 523 & $21 \%$ & 900151 & $20 \%$ & \\
\hline Second & 522 & $21 \%$ & 785385 & $16 \%$ & & 504 & $21 \%$ & 683200 & $16 \%$ & \\
\hline Lowest (Least advantaged) & 348 & $14 \%$ & 626538 & $13 \%$ & & 374 & $15 \%$ & 509704 & $12 \%$ & \\
\hline Remoteness & & & & & $<0.001$ & & & & & $<0.001$ \\
\hline Major City & 1232 & $50 \%$ & 3617002 & $72 \%$ & & 1216 & $50 \%$ & 3207391 & $72 \%$ & \\
\hline Inner regional & 933 & $38 \%$ & 858019 & $17 \%$ & & 945 & $39 \%$ & 766516 & $17 \%$ & \\
\hline Outer regional/Remote/Very remote & 276 & $11 \%$ & 556727 & $11 \%$ & & 276 & $11 \%$ & 462011 & $10 \%$ & \\
\hline Occupation Group & & & & & 0.66 & & & & & 0.46 \\
\hline Allied health & 11 & $0 \%$ & 56186 & $1 \%$ & & 34 & $1 \%$ & 142242 & $3 \%$ & \\
\hline Carers & 16 & $1 \%$ & 50425 & $1 \%$ & & 108 & $4 \%$ & 287442 & $7 \%$ & \\
\hline Cleaning & 36 & $1 \%$ & 67601 & $1 \%$ & & 71 & $3 \%$ & 112962 & $3 \%$ & \\
\hline Construction & 185 & $8 \%$ & 481448 & $10 \%$ & & 1 & $0 \%$ & 23653 & $1 \%$ & \\
\hline Education & 88 & $4 \%$ & 137470 & $3 \%$ & & 343 & $14 \%$ & 364921 & $9 \%$ & \\
\hline Electric/electronic & 75 & $3 \%$ & 210123 & $5 \%$ & & 0 & $0 \%$ & 7064 & $0 \%$ & \\
\hline Farming/Animal Worker & 178 & $7 \%$ & 142114 & $3 \%$ & & 60 & $2 \%$ & 68626 & $2 \%$ & \\
\hline Food preparation & 79 & $3 \%$ & 169586 & $4 \%$ & & 71 & $3 \%$ & 115877 & $3 \%$ & \\
\hline Food Service & 18 & $1 \%$ & 90777 & $2 \%$ & & 42 & $2 \%$ & 159860 & $4 \%$ & \\
\hline
\end{tabular}


Table 1 Comparisons between the AWES-Asthma sample and the Australian workforce [23] by gender (Continued)

\begin{tabular}{|c|c|c|c|c|c|c|c|c|c|c|}
\hline Gardening & 62 & $3 \%$ & 113707 & $2 \%$ & & 17 & $1 \%$ & 18715 & $0 \%$ & \\
\hline Hairdressers & 2 & $0 \%$ & 10931 & $0 \%$ & & 22 & $1 \%$ & 70677 & $2 \%$ & \\
\hline Manager-Administration & 871 & $36 \%$ & 1123391 & $24 \%$ & 0.01 & 1129 & $46 \%$ & 1654232 & $39 \%$ & 0.15 \\
\hline Manufacturing & 64 & $3 \%$ & 155192 & $3 \%$ & & 22 & $1 \%$ & 72262 & $2 \%$ & \\
\hline Mechanical Workers & 64 & $3 \%$ & 111689 & $2 \%$ & & 1 & $0 \%$ & 1681 & $0 \%$ & \\
\hline Metal Workers & 82 & $3 \%$ & 174438 & $4 \%$ & & 2 & $0 \%$ & 2574 & $0 \%$ & \\
\hline Mining & 27 & $1 \%$ & 67135 & $1 \%$ & & 0 & $0 \%$ & 6181 & $0 \%$ & \\
\hline Nurse/Medical & 45 & $2 \%$ & 81407 & $2 \%$ & & 227 & $9 \%$ & 290228 & $7 \%$ & \\
\hline Other & 23 & $1 \%$ & 151785 & $3 \%$ & & 11 & $0 \%$ & 96719 & $2 \%$ & \\
\hline Painting/Printing & 45 & $2 \%$ & 102195 & $2 \%$ & & 4 & $0 \%$ & 23348 & $1 \%$ & \\
\hline Retail & 143 & $6 \%$ & 485707 & $10 \%$ & & 205 & $8 \%$ & 585503 & $14 \%$ & \\
\hline Security/safety & 48 & $2 \%$ & 115691 & $2 \%$ & & 7 & $0 \%$ & 26264 & $1 \%$ & \\
\hline Technical/engineering & 37 & $2 \%$ & 87799 & $2 \%$ & & 40 & $2 \%$ & 62513 & $1 \%$ & \\
\hline Transport & 166 & $7 \%$ & 339713 & $7 \%$ & & 18 & $1 \%$ & 36282 & $1 \%$ & \\
\hline Wood workers & 76 & $3 \%$ & 135873 & $3 \%$ & & 2 & $0 \%$ & 2816 & $0 \%$ & \\
\hline
\end{tabular}

among farmers and animal workers (97 \% exposed), metal workers (96\%), wood workers (96\%), food preparation workers (92\%) and mechanical workers (92\%). Amongst females, the occupational groups with the highest prevalence of exposure were farmers and animal workers (100\%), carers (99\%), cleaners (96\%), food preparation workers (96\%) and nurses (92\%).

The most common asthmagen exposures among males (Table 3) were bioaerosols (29\% of the Australian workforce), metals (27\%), arthropods/mites (25\%), and latex

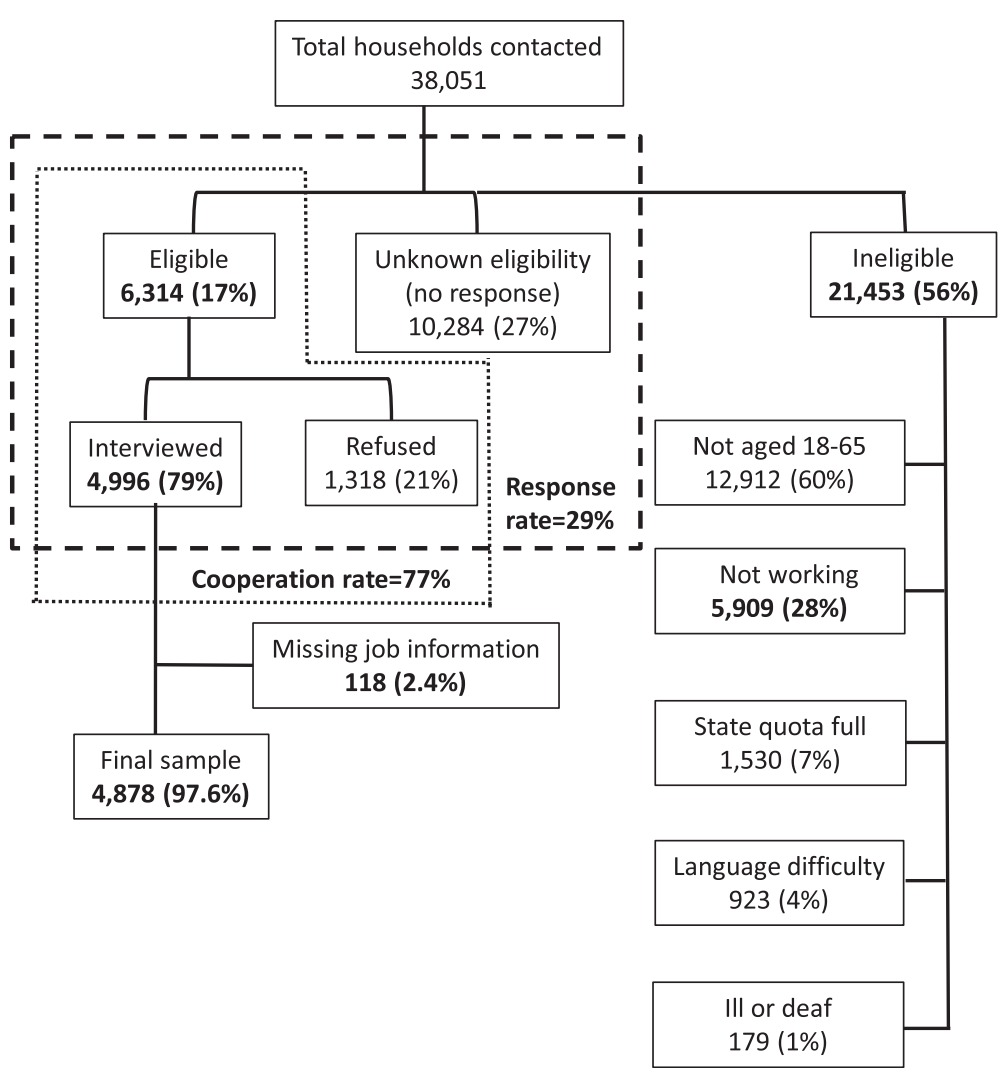

Fig. 1 Flow chart of responses to telephone survey cohort 
Table 2 Odds ratios (OR) and $95 \%$ confidence intervals (Cl) for association between demographic characteristics and probable exposure

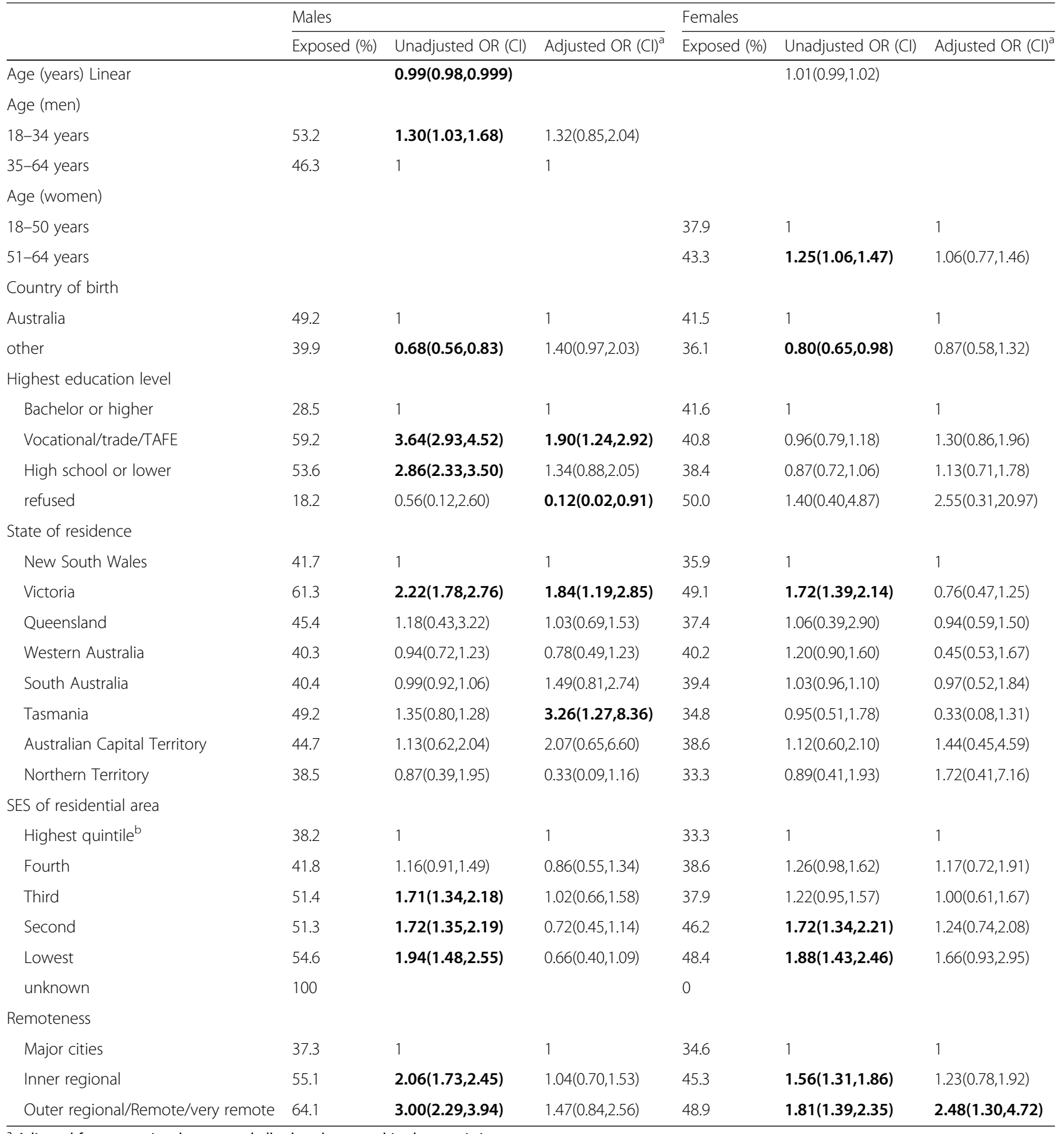

${ }^{a}$ Adjusted for occupational group and all other demographic characteristics

${ }^{b}$ SES - socioeconomic status (2 quintiles calculated from deciles of Areas Index of Relative Socio-economic Disadvantage [ABS])

Bold denotes statistically significant differences

(22\%). Among females (Table 4) the most common exposures were latex (25\%), industrial cleaning and sterilizing agents (20\%), bioaerosols (18\%) and arthropods/ mites (16\%). Exposure to isocyanates, which are wellrecognized asthmagens, was relatively rare $(4 \%$ among men and $<1 \%$ among women).
Additional file 1: Figure S1A shows the patterns for males, sorted by the two Euclidean distances, such that asthmagen groups with similar profiles of prevalence of exposure across all occupational groups are neighbours. In Additional file 1: Figure S1B, the patterns for females are shown, in the same order as for the males. In men, 
Table 3 Prevalence of probable exposure to each asthmagen group in the AWES-Asthma sample and approximate prevalence of exposure in the male Australian working population. Cl confidence interval

\begin{tabular}{|c|c|c|c|c|c|}
\hline \multirow[b]{2}{*}{ Asthmagen group } & \multicolumn{2}{|c|}{ Sample } & \multicolumn{3}{|c|}{ Extrapolated to Australian working population ${ }^{a}$} \\
\hline & $\mathrm{n}$ & $\%$ & $\mathrm{n}$ & $\%$ & $\mathrm{Cl}$ \\
\hline Any asthmagen & 1151 & 47.2 & 2781500 & 55 & 52 to 58 \\
\hline Bioaerosols & 633 & 25.9 & 1483000 & 29 & 27 to 32 \\
\hline Metals & 563 & 23.1 & 1358500 & 27 & 25 to 30 \\
\hline Arthropods or mites & 518 & 21.2 & 1234500 & 24 & 22 to 27 \\
\hline Latex & 451 & 18.5 & 1115500 & 22 & 20 to 25 \\
\hline Aldehydes & 364 & 14.9 & 829700 & 16 & 14 to 19 \\
\hline Industrial cleaning and sterilising agents & 264 & 10.8 & 683000 & 14 & 12 to 16 \\
\hline Derived from animals & 328 & 13.4 & 655800 & 13 & 11 to 15 \\
\hline Ammonia & 309 & 12.7 & 564600 & 11 & 10 to 13 \\
\hline Acrylates & 206 & 8.4 & 526800 & 10 & 9 to 12 \\
\hline Epoxy & 174 & 7.1 & 486400 & 10 & 8 to 12 \\
\hline Anhydrides & 191 & 7.8 & 433500 & 9 & 7 to 10 \\
\hline Other Reactive Chemicals & 142 & 5.8 & 366500 & 7 & 6 to 9 \\
\hline Foods & 121 & 5.0 & 359900 & 7 & 6 to 9 \\
\hline Biological Enzymes & 136 & 5.6 & 357400 & 7 & 6 to 9 \\
\hline Isocyanates & 106 & 4.3 & 283300 & 6 & 4 to 7 \\
\hline Derived from Plants-Other & 188 & 7.7 & 270200 & 5 & 4 to 7 \\
\hline Flour & 74 & 3.0 & 239400 & 5 & 4 to 6 \\
\hline Acids & 96 & 3.9 & 218300 & 4 & 3 to 6 \\
\hline Soldering & 75 & 3.1 & 214700 & 4 & 3 to 6 \\
\hline Wood Dusts & 86 & 3.5 & 200100 & 4 & 3 to 5 \\
\hline Amines & 47 & 1.9 & 123500 & 2 & 2 to 4 \\
\hline Derived from fish/shellfish & 36 & 1.5 & 113400 & 2 & 2 to 3 \\
\hline Pesticides & 59 & 2.4 & 112400 & 2 & 2 to 3 \\
\hline Flowers & 23 & 0.9 & 36800 & $<1$ & \\
\hline Ethylene Oxide & 14 & 0.6 & 34300 & $<1$ & \\
\hline Drugs & 7 & 0.3 & 20200 & $<1$ & \\
\hline Reactive dyes & 4 & 0.2 & 45 & $<1$ & \\
\hline
\end{tabular}

${ }^{a}$ Using age, remoteness and manager status for raked weighting

the occupational groups with highest prevalence of exposures are farming, food preparation, wood work, painting/printing and carers. In women, they are farming, food preparation, wood work, hairdressers, and cleaning. In men, bioaerosols, metal, arthropods, latex and aldehydes are the most common asthmagen groups, and in women they are latex, cleaning agents, arthropods, bioaerosols and ammonia.

In the lower left corner occupational and asthmagen groups with the lowest prevalence are clustered together. In men the occupational groups with low prevalences are security/safety, retail, transport, metal workers, and managers. In women they are education, manufacturing, mining, retail, transport, and manager. The asthmagen groups with the lowest prevalence in men were medicinal drugs, reactive dyes, ethylene oxide, flowers and pesticides and in women they were drugs, reactive dyes, epoxy, anhydrides and solder flux.

The Additional file 1 also shows the agents to which workers within each occupational group are simultaneously exposed, e.g. male metal workers are not only exposed to metal, but also to bioaerosols, aldehydes, acrylates, epoxy and anhydrides.

With regard to agents, the large molecular weight organic agents such as bioaerosols and arthropods and mites were more prevalent than exposure to smallermolecular weight agents although exposure to metals was common among men in occupational groups such as farming, painting/printing, electrical, metal and mechanical workers (Additional file 1). 
Table 4 Prevalence of probable exposure to each asthmagen group the AWES-Asthma sample and approximate prevalence of exposure in the female Australian working population. Cl confidence interval

\begin{tabular}{|c|c|c|c|c|c|}
\hline \multirow[b]{2}{*}{ Asthmagen group } & \multicolumn{2}{|c|}{ Sample } & \multicolumn{3}{|c|}{ Extrapolated to the Australian working population ${ }^{a}$} \\
\hline & $\mathrm{n}$ & $\%$ & $\mathrm{n}$ & $\%$ & $\mathrm{Cl}$ \\
\hline Any asthmagen & 984 & 40.4 & 1656300 & 37 & 34 to 40 \\
\hline Latex & 601 & 24.7 & 980700 & 22 & 20 to 25 \\
\hline Industrial cleaning and sterilising agents & 491 & 20.2 & 823500 & 19 & 16 to 21 \\
\hline Bioaerosols & 439 & 18.0 & 728900 & 16 & 14 to 19 \\
\hline Arthropods or mites & 398 & 16.3 & 676900 & 15 & 13 to 18 \\
\hline Biological Enzymes & 279 & 11.5 & 467300 & 11 & 9 to 12 \\
\hline Foods & 247 & 10.1 & 445900 & 10 & 8 to 12 \\
\hline Ammonia & 252 & 10.3 & 373500 & 8 & 7 to 10 \\
\hline Flour & 212 & 8.7 & 358900 & 8 & 7 to 10 \\
\hline Aldehydes & 201 & 8.3 & 307800 & 7 & 6 to 8 \\
\hline Derived from animals & 218 & 9.0 & 282900 & 6 & 5 to 8 \\
\hline Metals & 153 & 6.3 & 220700 & 5 & 4 to 6 \\
\hline Flowers & 85 & 3.5 & 147500 & 3 & 2 to 5 \\
\hline Acrylates & 65 & 2.7 & 125300 & 3 & 2 to 4 \\
\hline Derived from fish/shellfish & 64 & 2.6 & 105300 & 2 & 2 to 3 \\
\hline Pesticides & 51 & 2.1 & 75500 & 2 & 1 to 3 \\
\hline Derived from Plants-Other & 55 & 2.3 & 62600 & 1 & 1 to 2 \\
\hline Acids & 38 & 1.6 & 53700 & 1 & 1 to 2 \\
\hline Amines & 21 & 0.9 & 51100 & 1 & 1 to 2 \\
\hline Drugs & 7 & 0.3 & 24400 & $<1$ & \\
\hline Epoxy & 19 & 0.8 & 22700 & $<1$ & \\
\hline Isocyanates & 11 & 0.5 & 11500 & $<1$ & \\
\hline Other Reactive Chemicals & 5 & 0.2 & 7600 & $<1$ & \\
\hline Reactive dyes & 4 & 0.2 & 36 & $<1$ & \\
\hline Ethylene Oxide & 4 & 0.2 & 36 & $<1$ & \\
\hline Anhydrides & 2 & 0.1 & 13 & $<1$ & \\
\hline Soldering & 1 & 0.0 & 4 & $<1$ & \\
\hline Wood Dusts & 3 & 0.1 & 1 & $<1$ & \\
\hline
\end{tabular}

${ }^{a}$ Using age, remoteness and manager status for raked weighting

The most common exposure in our study was bioaerosols (29 \% males, $16 \%$ females). This group included moulds such as Alternaria, Chrysonilia sitophilia, Neurospora and Penicillium, where exposure was likely to have occurred mainly when people were in contact with rotting foodstuffs. In addition, cutting oils potentially contaminated with bacteria were included in this group. Exposure to bioaerosols was common in a wide range of jobs including farming and gardening, food preparation and service, cleaning, carers, and metal/electronics work.

Similar occupational groups were exposed to the arthropods/mites group which included all types of mite as well as caddisflies, crickets and locusts, flour moths, fruit flies, mealworms, sheep blowflies, and silkworms.
This exposure was found for $25 \%$ of males and $16 \%$ of females.

Metal exposure included exposure to the metal or compounds of aluminium, chromium, cobalt, nickel, platinum, rhodium, titanium, tin, tungsten carbide, vanadium, stainless steel, or zinc oxide, as well as gas metal arc welding on uncoated mild steel and welding fumes. About $26 \%$ of males and $6 \%$ females, mainly tradespeople, were exposed to one or more of these metals.

\section{Discussion}

This study provides much-needed information about the prevalence of exposure to asthmagens in Australian workplaces. These results will have significant implications for the prevention of occupational asthma, as they 
provide an important input to the determination of where to focus regulatory activities and inform strategies for risk reduction.

We found that about $47 \%$ of males and $40 \%$ of females were currently likely to be exposed to one or more asthmagens in their jobs. A multinational study found that $26 \%$ of subjects reported occupational exposure in their current job to "vapors, gas, dust or fumes" [8]. Our study investigated a wide range of exposures that were not included in this multinational study (such as latex, arthropods and mites, animal products, and various foods) so this may account for our prevalence being higher. In a Norwegian cohort, a job exposure matrix was applied to all jobs held for the previous 10 years to estimate exposure to biological dust, mineral dust and gas or fumes [9]. Exposure to any of the agents was seen in $62.4 \%$ of men and $58.6 \%$ of women at some time during the past 10 years. Job exposure matrices assign all people in the same job the same exposure [24] whereas our study was able to differentiate between workers in the same job who carried out different tasks.

Latex exposure was one of the few exposures found as commonly amongst females (25\%) as males (22\%). Latex exposure was assigned to respondents who reported wearing latex gloves, regardless of whether the gloves were powdered or not. Latex exposure is known to cause asthma, and efforts have been made to reduce exposure, including introducing powder-free latex gloves or replacement with nitrile gloves [25]. Exposure still seems relatively common in Australia, although it is unknown how well workers were able to differentiate the different types of glove.

Registries of occupational asthma have found common agents to be: isocyanates and latex in South Africa [26]; moulds, animal epithelia and flour, grain and grain mites in Finland [27]; wood dust in Australia [28]; and isocyanates, metal working fluids, adhesives, chrome, latex and glutaraldehyde in the United Kingdom [29]. Physician reporting of occupational asthma to voluntary registries is known to be an under-representation of the total number of cases, and may be biased by diagnosis being related to the presence of a commonly recognized or deemed cause [28]. A South Korean study which collected data from a range of sources (including physicians, surveillance systems and compensation schemes) found the most common agents to be isocyanates, flour/ grain, metal, reactive dyes, and solvents [30].

We used an automated version of the expert assessment method to obtain our estimates of exposure. It is not practical to monitor exposure in individual workplaces on a national level to estimate prevalence of exposure. Other estimates have been based on selfreported exposures but have been shown to result in reporting bias [8] and there are concerns that workers do not always know the specific components of materials with which they work. Job Exposure Matrices have also been used, but these result in all the workers in a particular job being allocated the same exposure, ignoring inter-individual variability, potentially resulting in an overestimation of the exposure prevalence. The expert assessment method used in this study [31] differentiates between people in the same job by asking respondents about tasks and processes. Experts then review the answers and assign exposures. We used OccIDEAS, which is based on this expert method, but automates the exposure assessment by using algorithms to assign the same exposure to the same combination of answers without the need for manual review of every case. This method provides individualized and consistent exposure assessment of all respondents based on their selfreported occupational tasks.

\section{Limitations}

We attempted to obtain a random sample of the population for this study. The distribution of our sample was reasonably similar to the Australian labour force, and we weighted by age group and remoteness when extrapolating our numbers. However, we only discovered the erroneous method of "random sampling" used by the commercial company after the data collection was complete. There is no way to know what bias arises from our sample over-representing people with last names beginning with $\mathrm{L}$ and $\mathrm{M}$ only. Some ethnicities may be under- or over-represented (e.g. Lee/Li or names with the prefix Mac or Mc) but this is difficult to quantify. Additional exploration of the data collected on country of birth found no differences of note between our sample and the Australian working population. Further, there is no reason to think that people with particular initials are preferentially selected into particular occupations, so we think it unlikely to bias the results.

We had no response to our phone call for about a quarter of the sample of phone numbers. We attempted to contact each number 10 times, and phone calls were made at different times of the day and on weekdays as well as weekends. However, it is likely that there was some selection bias with regard to particular occupations, particularly those who work away from home for extended periods such as long-haul truck drivers, and fly-in fly-out mine workers.

We decided to develop 27 groups for the 277 asthmagens [11] and based our groups broadly on the ones used in a previous job exposure matrix [32]. This meant, for example, that exposure to the group "Derived from animals" could have meant the person was exposed to any or all of 13 agents in the group including bat guano, casein, mice, frogs or cattle. We felt this was preferable to assessing each of the 277 asthmagens separately or 
concentrating only on a small number of specific agents. Further analyses of these data could examine exposure to one or more of the groups in more detail, including which of the specific agents were most common.

\section{Conclusions}

Occupational asthma is an ideal candidate for prevention and these results present clear opportunities for policy action which would be of practical benefit. We contend that these decisions should be based on evidence as to which agents are most commonly encountered in workplaces and which workers are most likely to be exposed to one or more asthmagens (e.g. farmers) which have not previously been available. Our study has provided some of this evidence and further analysis will show whether available controls are being used.

For pulmonary medicine specialists, our study provides an overall picture of which asthmagens are found in which occupations. While the pattern of use of some agents, such as isocyanates and latex, are well understood, our study provides a wider range range of possible causes for physicians to consider in their consultations with patients.

\section{Ethics approval and consent to participate}

This study was approved by the Curtin University Human Research Ethics Committee.

\section{Availability of data and materials}

The datasets supporting the conclusions of this article are available upon request to the corresponding author.

\section{Additional file}

Additional file 1: Figure S1. Occupational groups by asthmagen groups for (A) men, and (B) women. Groups are sorted by decreasing Euclidean distances in men as a measure of similar exposure and displayed for women using the same order of occupational groups and asthmagen groups as for men. The size of the dots represents the prevalence of exposure in each cell. (EtOH - Ethylene oxide, $d$ - derived, Reactives - Other reactive chemicals, Cleaning - Industrial cleaning and sterilizing agents, Arthropods - Arthropods and Mites). (PDF 135 kb)

\section{Abbreviations}

ANZSCO: Australian and New Zealand Standard Classification of Occupations; ARIA+: Accessibility/remoteness index of Australia; AWES: Australian Workplace Exposures Study; Cl: confidence interval; JSM: job specific module; OR: odds ratio; SEIFA: socio-economic indexes for areas disadvantage score.

\section{Competing interests}

The authors declare that they have no competing interests.

\section{Authors' contributions}

LF drafted this manuscript, directed the study and is responsible for its overall design. RNC and ED conducted statistical analyses under the direct supervision of LF. RNC, TD, DCG, AR, GPB, SP, JC and MJA were each involved in the design of the study. All authors provided feedback on the draft of this manuscript. All authors read and approved the final manuscript.

\section{Acknowledgements}

We gratefully acknowledge the advice provided by: Dr Jonathan Burdon, Dr Ryan Hoy, Dr Jan-Paul Zock, Associate Professor Jeremy Beach, Sandy Ashton, and Dr Jenny Job and Brett Bissett at SafeWork Australia. We thank Dr Ines

Florath for analysis and the development of the Similarity Exposure Profiles.

\section{Funding}

This study was funded by the National Health and Medical Research Council (\# 1056684) and SafeWork Australia. Lin Fritschi is supported by fellowships from the NHMRC and Cancer Council Western Australia.

\section{Author details}

${ }^{1}$ School of Public Health, Curtin University, GPO Box U1987, Perth, Western Australia 6845, Australia. ${ }^{2}$ Monash Centre for Occupational and Environmental Health, School of Public Health \& Preventive Medicine, Monash University, Melbourne, Victoria, Australia. ${ }^{3}$ Sydney School of Public Health, University of Sydney, New South Wales, Australia. ${ }^{4}$ School of Population Health, University of Western Australia, Perth, Western Australia, Australia.

Received: 21 January 2016 Accepted: 31 March 2016

Published online: 09 April 2016

\section{References}

1. Chan-Yeung M, Malo J. Aetiological agents in occupational asthma. Eur Respir J. 1994;7:346-71

2. Hoy RF, Burgess JA, Benke G, Matheson M, Morrison S, Gurrin L, Walters EH, Dharmage SC, Abramson MJ. Occupational Exposures and the Development of New-onset Asthma: A Population-based Cohort Study From the Ages of 13 to 44 Years. J Occup Environ Med. 2013;55:235-9.

3. Toren K, Blanc PD. Asthma caused by occupational exposures is common a systematic analysis of estimates of the population-attributable fraction. BMC Pulm Med. 2009;9:7

4. Donoghue AM, Frisch N, Ison M, Walpole G, Capil R, Curl C, Di Corleto R, Hanna B, Robson R, Viljoen D. Occupational asthma in the aluminum smelters of Australia and New Zealand: 1991-2006. Am J Ind Med. 2011;54: 224-31.

5. Baur X, Bakehe P. Allergens causing occupational asthma: an evidencebased evaluation of the literature. Int Arch Occup Environ Health. 2014;87: 339-63.

6. Newman Taylor A, Nicholson P, Cullinan P, Boyle C, Burge P. Guidelines for the prevention, identification and management of occupational asthma: Evidence review and recommendations. London: British Occupational Health Research Foundation; 2004.

7. Rantanen J, Lehtinen S. Work environment and occupational health in Finland. Helsinki: Finnish Institute of Occupational Health; 1992.

8. de Vocht F, Zock J-P, Kromhout H, Sunyer J, Anto JM, Burney P, Kogevinas M. Comparison of self-reported occupational exposure with a job exposure matrix in an international community-based study on asthma. Am J Ind Med. 2005;47:434-42.

9. Skorge TD, Eagan TM, Eide GE, Gulsvik A, Bakke PS. Occupational exposure and incidence of respiratory disorders in a general population. Scand J Work Environ Health. 2009;35:454-61.

10. Hansell A, Ghosh RE, Poole S, Zock JP, Weatherall M, Vermeulen R, et al. Occupational risk factors for chronic respiratory disease in a New Zealand population using lifetime occupational history. J Occup Environ Med. 2014; 56:270-80.

11. Crewe J, Carey R, Glass D, Peters S, Abramson MJ, Benke G, Reid A, Driscoll $\mathrm{T}$, Fritschi L. A comprehensive list of asthmagens to inform health interventions in the Australian workplace. Aust N Z J Public Health. 2016;40: 170-73

12. ABS: Australian Bureau of Statistics. Labour Force Australia. Canberra: Australian Bureau of Statistics; 2011

13. ABS: Labour Force Survey Standard Products and Data Item Guide. (Statistics ABo ed. Canberra: Australian Government Printer; 2015.

14. Galea S, Tracy M: Participation Rates in Epidemiologic Studies. Ann. Epidemiol. 2007:17:643-653.

15. Carey RN, Driscoll TR, Peters S, Glass DC, Reid A, Benke G, Fritschi L. Estimated prevalence of exposure to occupational carcinogens in Australia (2011-2012). Occup Environ Med. 2014;71:55-62. 
16. ABS. Socio-Economic Indexes for Areas (SEIFA). Canberra: Australian Bureau of Statistics; 2011.

17. ABS. Australian Statistical Geography Standard (ASGS) - Remoteness structure. Canberra: Australian Bureau of Statistics; 2011.

18. Fritschi L, Friesen MC, Glass D, Benke G, Girschik J, Sadkowsky T. OccIDEAS: Retrospective Occupational Exposure Assessment in Community-Based Studies Made Easier. J Environ Public Health. 2009;2009:5.

19. ABS. ANZSCO - Australian and New Zealand Standard Classification of Occupations, Version 1.2. Canberra: Australian Bureau of Statistics; 2013.

20. StataCorp. Stata Statistical Software: Release 14. College Station: StataCorp LP; 2015.

21. Abdolell M, LeBlanc M, Stephens D, Harrison RV. Binary partitioning for continuous longitudinal data: categorizing a prognostic variable. Stat Med. 2002;21:3395-409.

22. Dal Grande E, Chittleborough CR, Campostrini S, Tucker G, Taylor AW. Health Estimates Using Survey Raked-Weighting Techniques in an Australian Population Health Surveillance System. Am J Epidemiol. 2015;182:544-56.

23. ABS: Labour Force, Australia, Nov 2014. (Statistics ABo ed. Canberra 2014.

24. Siemiatycki J. Discovering occupational carcinogens in population-based case-control studies: review of findings from an exposure-based approach and a methodologic comparison of alternative data collection strategies. Recent Results Cancer Res. 1990:120:25-38.

25. LaMontagne AD, Radi S, Elder DS, Abramson MJ, Sim M. Primary prevention of latex related sensitisation and occupational asthma: a systematic review. Occup Environ Med. 2006;63:359-64.

26. Esterhuizen TM, Hnizdo E, Rees D. Occurrence and causes of occupational asthma in South Africa-results from SORDSA's Occupational Asthma Registry, 1997-1999. S Afr Med J. 2001;91:509-13.

27. Plipari R, Keskinen H. Agents causing occupational asthma in Finland in 1986-2002: cow epithelium bypassed by moulds from moisture-damaged buildings. Clin Exp Allergy. 2005;35:1632-7.

28. Elder D, Abramson M, Fish D, Johnson A, McKenzie D, Sim M. Surveillance of Australian workplace Based Respiratory Events (SABRE): notifications for the first 3.5 years and validation of occupational asthma cases. Occup Med-Oxford. 2004;54:395-9.

29. Bakerly ND, Moore VC, Vellore AD, Jaakkola MS, Robertson AS, Burge PS. Fifteen-year trends in occupational asthma: data from the Shield surveillance scheme. Occup Med (Lond). 2008;58:169-74.

30. Kwon SC, Song J, Kim YK, Calvert GM. Work-Related Asthma in Korea Findings from the Korea Work-Related Asthma Surveillance (KOWAS) program, 2004-2009. Allergy, Asthma Immunol Res. 2015;7:51-9.

31. Siemiatycki J, Day NE, Fabry J, Cooper JA. Discovering carcinogens in the occupational environment: a novel epidemiologic approach. J Natl Cancer Inst. 1981;66:217-25.

32. Kennedy SM, Le Moual N, Choudat D, Kauffmann F. Development of an asthma specific job exposure matrix and its application in the epidemiological study of genetics and environment in asthma (EGEA) Occup Environ Med. 2000;57:635-41.

\section{Submit your next manuscript to BioMed Central and we will help you at every step:}

- We accept pre-submission inquiries

- Our selector tool helps you to find the most relevant journal

- We provide round the clock customer support

- Convenient online submission

- Thorough peer review

- Inclusion in PubMed and all major indexing services

- Maximum visibility for your research

Submit your manuscript at www.biomedcentral.com/submit 